\title{
APRESENTAÇÃO
}

\section{REGRAR O TUMULTO DAS PALAVRAS, PENSAR AS PRÁTICAS DE ESCRITA DA NARRATIVA HISTÓRICA}

DOI: http://dx.doi.org/10.1590/2236-3459/85695

\author{
Maria Stephanou' \\ 'Universidade Federal do Rio Grande do Sul (Ufrgs), Porto Alegre/RS, Brasil \\ Editora de História da Educação
}

$\cos 8$

\begin{abstract}
Pensei num labirinto de labirintos, num sinuoso labirinto crescente que abrangesse o passado e o futuro e implicasse de algum modo os astros.
\end{abstract}

(BORGES, 2007).

V oltam os labirintos... Na ficção Borges inventa a imagem de um labirinto de labirintos. Na literatura ele pode assim jogar com as palavras e suas imagens refletidas. Não se trata aqui de fixar um sentido ou significado a essa invenção, mas de propor a epígrafe para pensar nosso ofício, irremediavelmente atado à costura de palavras em textos historiográficos. Haverá labirintos de labirintos nos processos em que estamos imersos como historiadores? Os labirintos das "palavras arquivadas" (FARGE, 1989), das palavras ditas e dos não ditos do passado e das palavras que escolhemos para fazer falar nossos arquivos e dispô-los em textos?

A cada vez, a cada número, e não menos nesta edição 56 de História da Educação, o leitor poderá observar algumas "batalhas das palavras", na acepção de Jacques Rancière (2014). Umas palavras foram habilmente domadas, outras ainda estão em disputa ou em excesso, algumas estão desgarradas, perdidas, escorridas, mais outras orquestram uma arquitetura poética ou um hábil argumento que nos surpreende porque formula o não pronunciado até o momento. Assim, diversas estão habilmente costuradas, lançam luz a tramas complexas e inspiram a percorrer seus labirintos. 
Quais astros habitam o universo contemplado pelos historiadores da educação? Como são observados, inquiridos, compreendidos? Quais inteligibilidades do passado são tecidas? Essas questões não são novas, muitos autores escreveram sobre as mesmas, mas elas persistem propondo atenção sobre a especificidade do tempo e do conhecimento que produzimos. Como nos embrenhamos no sinuoso labirinto do tempo escoado, do tempo presente e do devir? Cada artigo da edição 56 oferece algumas pistas às respostas possíveis. Vale lembrar que se o labirinto é sinuoso, é também Borges que nos ensina que "os homens só compreendem os labirintos que eles mesmos constroem".

Palavras orquestradas em labirintos, palavras em tumulto, palavras excessivas, tecidas em narrativas apaziguadas ou belicosas, que outras palavras, menos precárias ou menos recorrentes, podemos eleger para expressar nossas intuições potenciais dos fenômenos e acontecimentos que examinamos? O fazer historiográfico não está imune aos embates e armadilhas de sua necessidade de fazer-se escrita e discurso específico.

Recentemente, o Santander Cultural de Porto Alegre acolheu a exposição Museu Desmiolado, inspirada no livro homônimo de Alexandre Brito (2017), filósofo, músico, letrista, escritor e poeta. A exposição procura transmutar em imagens, movimentos, alegorias e materialidades os poemas inusitados e desmiolados que jogam com a polissemia de palavras cuidadosamente eleitas em cada estrofe.

Assim, uma mirada a outras inteligências, para além da inteligência historiadora (FARGE, 2011), pode vir a provocar muitas reflexões a partir da sinuosidade das tramas \& poemas de Brito e de como desafiam, para nós, às voltas com a escrita da História, a natureza da ordem de nossas narrativas (STEPHANOU, 2018, p. 2). Nos faria bem um pouco dessa leve insensatez das formulações poéticas? Temos lugar, na narrativa histórica, para um jogo lúdico e tumultuado das palavras? Vejamos! Que cada leitor faça as suas peripécias de associação.

O autor cataloga palavras que "tomaram chá de sumiço" (fazemos algo semelhante?) e em seu museu das palavras esquecidas, elas reaparecem e permanecem vivas. Serão palavras imaginárias? Se esquecer é também perder, como fazemos com palavras importantes que nos escapa? Insistimos em não esquecê-las? Procuramos os sentidos que seus falantes Ihes atribuíam? Poetiza Brito: "certas palavras esquecidas / são palavras de imensa valia [...] e tem aquelas que se foram faz muito tempo / caíram em desuso, desapareceram no vento" (2017, p. 36). Eis que deparamos com a historicidade das palavras e sua delicada existência.

O autor cria ainda o intrigante museu invertido, onde "pensar o contrário / como faz o espelho / de trás pra frente / do fim pro começo" [...] ler pelo avesso / ler invertido / afia o tino / excita os sentidos / do fim ao princípio" (BRITO, 2017, p. 24). Agora, é a imperiosa necessidade de pensarmos diferentemente das interpretações e mitos reificados do passado, duvidarmos das continuidades soberanas e, de forma invertida, pensarmos nos acasos, nos acidentes, nas contingências e nos desníveis (RAGO, 2002).

Há também o "museu dos relógios parados", "que exibem / sem qualquer possibilidade de erro / o exato momento de um instante no tempo" (BRITO, 2017, p. 40). E, finalmente, o museu do que ficou para trás, cujo poema nos faz deparar com figuras de retórica e maquinações das palavras, nos oferta, dizemos nós inadvertidamente, com pensamentos muito caros à operação historiográfica: "mas as coisas que se foram não desaparecem do mapa / não viram pó, não evaporam no ar" (BRITO, 2017, p. 44). Eis que 
persistem seus fios e rastros, seus usos em textos entranhados de história (GINZBURG, 2007).

Os artigos reunidos neste número 56 não guardam relações ulteriores entre si; a associação está estabelecida pela composição que os enfeixa em um número único, que lançamos antecipado. Quantas boas histórias, ou serão bons enredos, são apresentados, atravessando os séculos XIX e XX, a partir dos fios produzidos pelas análises que compõem essa edição? Suas idéias terão atingido "a forma alada mais rara" (BRITO, 2017)?

[...] os que se interessam pela história, e são muitos, brigam com a palavra. (RANCIĖRE, 2014, p. 1).

É da matéria-texto, do regramento de modos de interpretação e formas de escritura que palavras tumultuadas foram convertidas em textos que socializamos, alguns em dois idiomas. Expressam pensamentos, incertezas, tempos, arquivos, temas de estudo, análises e reflexões que acometeram os dezoito autores, filiados a diferentes instituições do Brasil, Colômbia, Espanha e Portugal, em seus percursos de pesquisa e movimentos de responder aos labirintos que construíram. Temos, ainda, uma entrevista, uma resenha e um documento inédito.

Carlota Boto, historiadora, professora da USP e pesquisadora de reconhecida competência no campo da história da educação luso-brasileira, de uma rara habilidade para orquestrar palavras e traduzir pensamentos em cuidadosas narrações históricas é entrevistada por Fernando Cezar Ripe e Giana Lange do Amaral. Seu itinerário como intelectual do campo permite vislumbrar os movimentos desdobrados no tempo e de como acontece de se fazer pesquisadora e pesquisa em História da Educação.

Ainda nesse número 56, Carlota Boto, juntamente com Suzana Lopes de Albuquerque, examinam o método Castilho no Brasil do século XIX. Chamamos a atenção para um aspecto em especial: a circulação transnacional de métodos de ensino como parte das ideias pedagógicas da Modernidade.

Quatro artigos tomam como arquivo principal da operação historiográfica impressos que caracterizamos como periódicos. Sugerem que os impressos como documentos por excelência das investigações persistem como escolha de diversos estudos em história da educação. Também indicam quais os avanços e repertórios constituídos no campo, e as diferentes entradas possíveis para análise dos mesmos, seja como objetos em si mesmos, seja como documentação privilegiada para uma diversidade de problematizações.

Um dos artigos com destaque aos impressos é de Xavier Motilla Salas e Sara González Gómez, pesquisadores espanhóis, que abordam a imprensa ilustrada na ilha de Mallorca (Espanha), a partir do exame de fundos fotográficos de diversas revistas ilustradas das três primeiras décadas do século XX. Novamente podemos observar a circulação transnacional de práticas da imprensa gráfica e do uso da fotografia, o que nos pode inspirar em outras pesquisas sobre "revistas ilustradas", que em outros contextos inscrevam-se no mesmo registro temporal. Somam-se a outros autores que apontam potencialidades e usos dessa documentação na história da educação.

A imprensa é mais uma vez o centro das reflexões, dessa feita como imprensa pedagógica - revista Escuelas de España (1929-1936) - de pesquisadores espanhóis, Rosa 
Ortiz de Santos e Luis Torrego Egido. Assinalam a abordagem ainda escassa desse periódico pelos estudos histórico-educativos, o que os leva, de certa forma, a uma minuciosa descrição desse documento com intuito de ressaltar seu caráter de patrimônio e memória da educação.

Um terceiro estudo associado aos impressos é o de Maria do Rosário Longo Mortatti, pesquisadora brasileira, aborda a literatura infantil e suas intersecções com o ensino de leitura e escrita, a partir da análise da Seção "Literatura infantil" da Revista de Ensino da Associação Beneficente do Professorado Público Paulista, entre 1902 a 1918. Igualmente neste artigo podemos analisar a circulação transnacional de idéias e concepções, expressas nas traduções/adaptações, paráfrases ou textos originais de autores brasileiros ou estrangeiros contemplados pela seção examinada pela autora.

Eduard Esteban Moreno, pesquisador colombiano, focaliza dois periódicos, que o autor adjetiva como "revolucionários e radicais", em circulação nas primeiras décadas do século XX, no Brasil e na Colômbia: o periódico La Humanidad (1925-1927); e o periódico A Plebe (1917-1920).

Outros temas de investigação comparecem nesse número 56. Destacam-se os discursos, os agentes, os eventos privilegiados, a história de disciplinas, níveis de ensino, currículo e instituições escolares. Os séculos XIX e XX, e este último em especial, situam os demais sete artigos.

Ivanilson Bezerra da Silva, pesquisador brasileiro, em artigo sobre Horace Lane, consultor da instrução pública paulista e sua participação na Exposição de St. Louis, detémse sobre o período 1885-1912. Aborda a atuação de agentes sociais e a realização de um evento emblemático, uma exposição internacional, a partir de documentação ainda pouco focalizada nos estudos de história da educação.

Jefferson da Costa Soares e Gustavo da Motta Silva, pesquisadores brasileiros, detém-se na compreensão da trajetória de agentes da educação de condição peculiar na hierarquia de uma instituição prestigiosa de ensino secundário: os professores suplementares do Colégio Pedro II, atuantes entre 1927 e o período do Estado Novo.

Currículo e disciplinas são historicizados em dois artigos. De uma parte, os pesquisadores brasileiros, Eva Maria Siqueira Alves e João Paulo Gama Oliveira, abordam a história das Ciências Físicas, Químicas e Naturais como conteúdos e programas curriculares no Ensino Secundário de Sergipe no período de 1882 a 1950. Em outra análise, Daniela Nienkötter Sardá, pesquisadora brasileira, detém-se nas especificidades da história do ensino da Filosofia no sistema escolar francês e brasileiro. Em um aspecto o artigo que segue se aproxima com o texto de Daniela Sardá: as relações entre agentes de educação, franceses e brasileiros, e suas concepções e propostas pedagógicas. Instituição escolar e modalidade de ensino comparece no artigo das pesquisadoras brasileiras Valeska Alessandra de Lima e Doris Bittencourt Almeida, que analisam as classes experimentais secundárias em um Colégio de Aplicação de universidade pública entre 1959 e 1981, experiência de ensino inspirada em iniciativas francesas no ensino secundário.

Ariel Feldman e Marina Feldman, pesquisadores brasileiros, são autores de artigo que examina uma história do tempo presente, qual seja, o modo particular como o imaginário social da democracia reverberou na municipalização do Ensino Fundamental no Brasil, fenômeno situados nas décadas de 1980 e 1990.

A edição 56 conta, ainda, com uma resenha e um documento. A resenha, escrita 
por Mariano González-Delgado, pesquisador espanhol, tem como tema central a formação de professores e reporta-se à obra Identidades docentes: La renovación del oficio de enseñar, publicada na Espanha em 2017 e organizada por Teresa González Pérez, com a participação de diferentes autores em oito capítulos.

Carlos Manique, pesquisador português, seleciona e apresenta com argúcia o documento intitulado Discursos proferidos pelo Rei D. Pedro $V$ nas sessões solenes de atribuição de prémios na Escola Real de Mafra (1858-1860), Portugal. Nos oferta, assim, uma indiscutível contribuição à história luso-brasileira da educação. $O$ autor indica, com diferentes argumentos, como podemos antever nesse documento o fato de que o monarca não apenas estava bem inteirado dos assuntos pedagógico-educacionais de seu tempo, como também enfrentou muitas dificuldades para propagar seu pensamento educacional e a modernidade no panorama da nação portuguesa.

Finalmente, registramos para o presente e para a posteridade da história de nosso periódico, que a edição 56 foi finalizada no momento em que o SciELO torna público, aos editores e comunidade científica, o documento Guia de boas práticas para o fortalecimento da ética na publicação científica, documento que servirá de padrão para todos os periódicos das coleções da Rede SciELO e que é pautado pelas normas e recomendações de padrões de ética e responsabilidade na comunicação científica estabelecidas pelas instituições nacionais e internacionais. Dentre os itens de regulação, o guia define que "tudo o que é publicado no periódico, assim como as ações corretivas que se façam necessárias, são de responsabilidade do editor chefe", daí porque as responsabilidades do editor-chefe englobem a implementação da política editorial, a supervisão do processo editorial e as relações do periódico com os autores, pareceristas, leitores, indexadores, agências de apoio à pesquisa, a comunidade científica e o público geral.

Como repercussão mais imediata, fica o desafio de promovermos uma reflexão coletiva sobre os rumos da revista, avançarmos no delineamento da política editorial, assegurarmos a transparência dos processos de submissão e avaliação, bem como a necessidade de um estatuto que possa assegurar a continuidade e a excelência de História da Educação/Asphe.

\section{Referências}

BORGES, Jorge Luis. Ficções. São Paulo: Companhia das Letras, 2007.

BRITO, Alexandre. Museu desmiolado. Porto Alegre: Editora Projeto, 5.ed., 2017.

FARGE, Arlette. De la lecture des archives de police du XVIIle siècle à la construction d'objets pour l'histoire In: COHEN, Évelyne; GOETSCHEL, Laurent M.; ORY, Pascal. Dix ans d'histoire culturelle. Villerbaune: Presses de l'enssib, cop. 2011. p. 101-109.

Le gôut de l'archive. Paris: Éditions du Seuil, 1989.

GINZBURG, Carlo. Os fios e os rastros: verdadeiro, falso, fictício. São Paulo:

Companhia das Letras, 2007.

RAGO, Margareth. Libertar a História. In: RAGO, M.; ORLANDI, L.B.L.; VEIGA-NETO, A. Imagens de Foucault e Deleuze: ressonâncias nietzschianas. Rio de Janeiro: DP\&A, 2002.

RANICIÈRE, Jacques. Os nomes da história: ensaio de poética do saber. São Paulo: Editora Unesp, 2014. 
SCIELO. Guia de boas práticas para o fortalecimento da ética na publicação

científica. Disponível em: <http://www.scielo.org/local/content/pdf/Guia\%20de\%20Boas\% 20Praticas\%20para\%200\%20Fortalecimento\%20da\%20Etica\%20na\%20Publicacao\%20C ientifica.pdf>

STEPHANOU, Maria. Os historiadores e as vicissitudes do tempo: perceber, imaginar, eleger, compreender, construir. Hist. Educ. (Online). Porto Alegre, v. 22, n. 54, jan./abr. 2018. p. 01-07.

MARIA STEPHANOU é professora Titular da Faculdade de Educação da Universidade Federal do Rio Grande do Sul (Ufrgs). Pesquisadora do CNPq, atua junto ao Programa de Pós-Graduação em Educação na linha de pesquisa História, memória e educação. Doutora em Educação pela Ufrgs, realizou seu pós-doutoramento junto ao Institut Français d'Éducation (IFÉ), França. Atua como editora de História da Educação desde 2011.

Endereço: Rua Dr. João Palombini, 144 A, 91751-150, Porto Alegre/RS, Brasil. E-mail: mastephanou@gmail.com 